\title{
Folato, Vitamina B12 e Ferritina Sérica e Defeitos do Tubo Neural
}

\author{
Folate, Vitamin B12, Serum Ferritin and Defects of the Neural Tube
}

Gizele Thame ${ }^{1,2}$, Elvira Maria Guerra Shinohara ${ }^{2}$ Hosana Gonçalves dos Santos ${ }^{2}$, Antonio Fernandes Moron ${ }^{1,3}$

\begin{abstract}
RESUM0
Objetivo: verificar os níveis de folatos, vitamina B12 e ferritina em pacientes cujos fetos apresentaram defeitos de tubo neural (DTN). O folato sangüineo e a vitamina B12 atuam como cofatores para as enzimas envolvidas na biossíntese do DNA. A interrupção deste processo pode impedir o fechamento do tubo neural. A suplementação vitamínica contendo folato pode reduzir as taxas de ocorrência de defeitos de tubo neural, embora exista a preocupação de que esta prevenção possa mascarar a deficiência de vitamina B12.

Métodos: dosagens de vitamina B12 e ferritina pelo método de enzimaimunoensaio com micropartículas e a dosagens de ácido fólico pelo método de captura iônica (IMx ABBOTT). Resultados: a porcentagem de gestantes com deficiência de vitamina B12 (níveis séricos < $150 \mathrm{pg} / \mathrm{ml}$ ) foi de $11,8 \%$. Não houve nenhum caso de deficiência de folato (niveis séricos < $3,0 \mathrm{ng} / \mathrm{ml}$ ). A prevalência de gestantes com deficiência nos estoques de ferro foi de $47,1 \%$ (níveis séricos < $12 \mathrm{ng} / \mathrm{ml}$ ).

Conclusões: com os resultados encontrados neste estudo (prevalência de 11,8\% de deficientes em vitamina $\mathrm{B} 12$ e $0 \%$ de deficiência de folato), sugerimos que a suplementação se realize após a determinação da vitamina $B 12$ sérica.
\end{abstract}

PALAVRAS-CHAVE: Pré-natal. Ácido fólico. Suplementação vitamínica. Malformações fetais. Defeitos do tubo neural.

\section{Introdução}

Durante a gestação ocorrem ajustes metabólicos para proporcionar o melhor ambiente para um desenvolvimento fetal normal. A nutrição inadequada pode resultar em retardo do crescimento, resistência reduzida a doenças

\footnotetext{
Instituições onde o trabalho foi desenvolvido:

${ }^{1}$ Faculdade de Saúde Pública da USP

${ }^{2}$ Instituto Adolfo Lutz

${ }^{3}$ Setor de Medicina Fetal da disciplina de Obstetrícia da UNIFESP, Escola Paulista de Medicina

Correspondência:

Gizele Thame

R. Aibi, 146 - ap. 62 Alto da Lapa

05054-010 - São Paulo - SP

e-mail: rasaquel@sol.com.br
}

infecciosas, interferindo no desenvolvimento da criança $^{12}$.

Neste aspecto o folato sangüíneo, o ferro e a vitamina B12 têm fundamental importância participando de reações indispensáveis à formação de novos tecidos. Na gestação, a eritropoiese materna está aumentada e os tecidos do feto estão se formando rapidamente.

A vitamina $\mathrm{B} 12$ é cofator na conversão do metilmalonil coenzima A (CoA) em succinil CoA, bem como na sintese de metionina, a partir da homocisteína e, juntamente com o folato, é necessária para a síntese de DNA. Há algumas condições em que se manifestam baixos níveis de vitamina B12 sérica como gestação, vegetarianismo, gastrectomias, deficiência 
pancreática e idade avançada ${ }^{9}$.

A ferritina é conhecida desde 1937 e sua presença era referida somente em baço, fígado e medula óssea. Entretanto, com o desenvolvimento de técnicas de radioimunoensaio, verificou-se existir também sob a forma circulante plasmática e os valores correlacionam-se significativamente com os depósitos orgânicos. Tornou-se importante determinar os níveis plasmáticos pois é um indicador do ferro armazenado e, por extensão, do estado nutricional ${ }^{21}$.

O ácido fólico participa de numerosas reações metabólicas indispensáveis para a síntese normal de $D_{N A}{ }^{18}$ e sua deficiência tem sido relacionada com os defeitos de tubo neural (DTN) e são a segunda causa mais comum de morte perinatal em razão de defeitos de nascimento no Reino Unido e conduzindo a considerável morbidez na infância ${ }^{4}$.

Nos Estados Unidos os DTN ocorrem em aproximadamente 1 de cada 1000 nascimentos. Na China, as taxas variam de 6 a 13 por 1.000 nascimentos, seguido pela Irlanda com 6 por 1.000 nascimentos ${ }^{19}$. Na cidade de São Paulo, o Estudo Colaborativo Latino-americano de Malformações Congênitas (ECLAMC) registrou 1 caso de DTN em cada 800 nascimentos, no período de 1982 a $1984^{6}$.

O diagnóstico pré-natal de DTN pode ser realizado a partir da $11^{\mathrm{a}}$ semana de gravidez e principalmente no início do segundo trimestre, a partir de ultra-sonografia e da dosagem de alfafetoproteina plasmática e no líquido amniótico e acetilcolinesterase no líquido aminiótico. Mais de 90\% dos casos de DTN ocorrem em mulheres que não são identificadas como de risco para estas anomalias. Por outro lado, a taxa de recorrência é extremamente alta, variando de 2 a $5 \%{ }^{8}$.

O processo de formação do tubo neural ocorre em duas etapas distintas denominadas de neurulação primária e secundária. A neurulação primária é a formação do tubo neural da região lombar alta até a região craniana. No início da gestação (24 a 28 dias após concepção), a placa neural se fecha, formando o tubo neural. A estrutura final abrange a coluna vertebral e o cérebro. O fechamento precoce incompleto resulta em espinha bífida, e o fechamento tardio, em anencefalia. A neurulação secundária é a formação do tubo neural da região lombar e sacral e se completa por volta da sétima semana de gestação ${ }^{15}$.

O interesse na relação entre vitaminas e DTN cresceu a partir de relatos de Smithells et al. com uma redução acentuada da ocorrência de DTN em pacientes com suplementação vitamínica materna $^{20}$. A partir daí, os estudos evidenciaram os benefícios da suplementação com folato para os defeitos de fechamento do tubo neural.

Em 1993, numa tentativa de colaborar com a diminuição dos DTN, o "US Department of Health and Human Services" e a "Food and Drug Administration" decidem suplementar produtos em grão nos Estados Unidos com ácido fólico ${ }^{7}$.

Em 1994 foi organizado um simpósio sobre $\mathrm{DTN}^{4}$, acentuando o debate em torno da fortificação alimentar e da suplementação vitamínica, permanecendo algumas controvérsias quanto ao uso de folato na gestação.

Page et al. em 1997, recomendaram que o consumo diário de folato total em mulheres não deve exceder 1,0 mg. A razão para esse limite está na preocupação com doses mais altas pois podem agravar a deficiência de vitamina B12 e que, quando esta deficiência não é descoberta e tratada, pode ocorrer dano neurológico irreversível ${ }^{17}$.

Dentre as anemias carenciais em gestantes a deficiência de ferro, ácido fólico ou vitamina B12 são as mais freqüentes. Em função das divergências encontradas na literatura a respeito da suplementação com ácido fólico, da escassez destes estudos no Brasil e por se tratar de um problema de saúde pública, achamos importante verificar estes níveis no soro de gestantes portadoras de fetos com DTN.

\section{Material e Métodos}

\section{Pacientes}

Foram analisados os soros de dezessete gestantes atendidas no período de fevereiro a outubro de 1997 na assistência pré-natal no Setor de Medicina Fetal do Hospital São Paulo, Disciplina de Obstetrícia da UNIFESP - EPM, por ocasião da realização da ultra-sonografia, após a confirmação de defeitos de tubo neural em seus fetos.

Todos os casos foram de primeira ocorrência de DTN. A idade gestacional média na data da coleta sangüinea foi de 30,6 semanas com data mínima de 21 semanas e máxima de 38 semanas. Outras características das gestantes estão listadas na Tabela 1 .

Tabela 1 - Características das gestantes portadoras de fetos com DTN

\begin{tabular}{llll}
\hline & & $\mathrm{n}$ & $\%$ \\
Média de idade & $24,5( \pm 6,1)$ & & \\
Escolaridade & $1^{\circ}$ grau & 9 & 52,9 \\
& $2^{\circ}$ grau & 7 & 41,2 \\
& superior & 1 & 5,9 \\
Número de gestações & primigesta & 8 & 47,1 \\
& multigesta & 9 & 52,9 \\
Defeitos de tubo neural & anencefalia & 4 & 23,5 \\
& encefalocele & 5 & 29,4 \\
& meningomielocele & 8 & 47,1 \\
\hline
\end{tabular}

\section{Métodos}

Após as explicações a respeito da natureza do experimento e obtidas as autorizações das 
gestantes, foram colhidos $10 \mathrm{ml}$ de sangue venoso da face anterior do antebraço para as determinações laboratoriais.

Parte do sangue coletado $(7 \mathrm{ml})$ foi colhido em tubo seco que, após retração do coágulo, foi centrifugado a $2.500 \mathrm{rpm}$ por 10 minutos, o sobrenadante depositado em tubos plásticos tipo "Eppendorf" e posteriormente congelado a $-40^{\circ} \mathrm{C}$. O soro foi utilizado para determinação dos níveis de folato, vitamina B12 e ferritina. Outros $3 \mathrm{ml}$ de sangue foram colhidos em tubo com anticoagulante (EDTA) para a realização do eritrograma.

As determinações do número dos eritrócitos, da concentração de hemoglobina e do volume corpuscular médio (VCM) foram realizadas em aparelho Counter T890, no mesmo dia da coleta sangüínea.

As determinações séricas de ferritina, vitamina B12 e ácido fólico foram realizadas por meio de métodos imunológicos, em duplicatas usando-se 3 controles. A determinação da ferritina sérica foi realizada pelo método de enzimaimunoensaio com micropartículas (ELISA de captura); a concentração de vitamina B12 foi determinada por meio da utilização do fator intrínseco ligado a micropartículas (ligante específico) e o ácido fólico sérico foi determinado pelo método de captura iônica. Os resultados foram quantificados segundo os valores de referência indicados pelo fabricante (IMx ABBOTT).

Foram consideradas deficientes em ácido fólico as gestantes com valores inferiores a $3 \mathrm{ng} / \mathrm{ml}$ segundo o padrão da OMS, $1968^{22}$; deficientes em ferro, quando as taxas encontradas de ferritina sérica foram menores que $12 \mathrm{ng} / \mathrm{ml}$ segundo a INACG $^{10}$ e para a vitamina B12, utilizamos valores inferiores a $150 \mathrm{pg} / \mathrm{ml}$ segundo a OMS, $1970^{16}$.

Na Tabela 2 são apresentados os critérios para a caracterização das deficiências de vitamina B12, folato e ferro.

Tabela 2 - Critérios utilizados para caracterizar deficiênicas séricas de vitamina B12, folato e ferritina.

\begin{tabular}{lccc}
\hline Interpretação & B12 (pg/ml) & Folato $(\mathrm{ng} / \mathrm{ml})$ & Ferritina $(\mathrm{ng} / \mathrm{ml})$ \\
\hline Deficientes & $<150$ & $<3,0$ & $<12,0$ \\
Duvidosos & $150-200$ & $3,0-5,9$ & $12,0-20,0$ \\
Adequados & $>200$ & $>6,0$ & $>20,0$ \\
\hline
\end{tabular}

Fontes: OMS, $1970^{16}$; OMS, $1968^{22}$ e INACG, $1985^{10}$.

Resultados

Os resultados indicam que o valor médio da vitamina B12 nas gestantes com fetos acometidos por DTN foi de $301,5 \mathrm{pg} / \mathrm{ml}$ com desvio padrão de $\pm 109,1$, sendo que o valor mínimo foi de 122,0 $\mathrm{pg} / \mathrm{ml}$ e o máximo foi de $521,0 \mathrm{pg} / \mathrm{ml}$. A porcentagem de deficiência de vitamina B12 considerando o critério de níveis séricos menor que $150 \mathrm{pg} / \mathrm{ml}$ foi de $11,8 \%$.

O valor médio do folato sérico nestas gestantes foi de $5,6 \mathrm{ng} / \mathrm{ml}$ com dp $\pm 2,0$ e os valores mínimo e máximo oscilaram entre 3,2 e 10,0 ng/ml. Não houve nenhum caso de deficiência de folato com o critério de níveis séricos menor que $3,0 \mathrm{ng} / \mathrm{ml}$.

A média encontrada nos níveis de ferritina sérica foi de $17,5 \mathrm{ng} / \mathrm{ml} \mathrm{com} \mathrm{dp} \pm 15,4$. O menor valor encontrado foi de $5,33 \mathrm{ng} / \mathrm{ml}$ e o valor mais alto foi de $65,5 \mathrm{ng} / \mathrm{ml}$. A prevalência de gestantes com deficiência no estoques de ferro foi de $47,1 \%$, adotando o critério de níveis séricos menor que $12 \mathrm{ng} / \mathrm{ml}$.

Na Tabela 3 são apresentadas as idades das gestantes, as idades gestacionais e os níveis séricos de vitamina B12, ácido fólico e ferritina e os respectivos valores do VCM. Na amostra estudada, não parece haver tendência de diminuição nos valores das concentrações séricas no decorrer da gravidez. Observa-se que houve uma distribuição aleatória de DTN segundo as idades das gestantes, com idade mínima de 15 anos e máxima de 39 anos. Nota-se que os valores do VCM estão dentro da faixa de normalidade nos 17 casos, independente de haver deficiência de vitamina B12.

\begin{tabular}{|c|c|c|c|c|c|}
\hline Idade & $\begin{array}{c}\text { Idade } \\
\text { gestacional } \\
\text { ( semanas ) }\end{array}$ & $\begin{array}{c}\text { Vitam. B12 } \\
\text { ( pg/ml ) }\end{array}$ & $\begin{array}{c}\text { Acido fólico } \\
\text { ( } \mathrm{ng} / \mathrm{ml})\end{array}$ & $\begin{array}{l}\text { Ferritina } \\
(\mathrm{ng} / \mathrm{ml})\end{array}$ & $\begin{array}{l}\text { VCM } \\
\text { ( fl ) }\end{array}$ \\
\hline 18 & 21 & 274 & 3,8 & 18,3 & 93,0 \\
\hline 39 & 23 & 161 & 3,8 & 5,3 & 93,3 \\
\hline 19 & 25 & 380 & 6,2 & 21,9 & 102,4 \\
\hline 15 & 26 & 361 & 4,3 & 6,8 & 92,4 \\
\hline 26 & 27 & 366 & 4,2 & 20,1 & 93,3 \\
\hline 30 & 28 & 147 & 6,6 & 42,7 & 96,5 \\
\hline 23 & 28 & 521 & 8,2 & 14,1 & 82,0 \\
\hline 17 & 29 & 377 & 4,4 & 12,7 & 91,6 \\
\hline 29 & 30 & 350 & 4,6 & 13,9 & 96,4 \\
\hline 19 & 31 & 179 & 8,7 & 5,8 & 83,6 \\
\hline 31 & 33 & 296 & 3,6 & 7,3 & 94,3 \\
\hline 28 & 33 & 277 & 5,3 & 10,7 & 88,2 \\
\hline 24 & 36 & 441 & 5,8 & 8,1 & 97,1 \\
\hline 26 & 37 & 303 & 5,0 & 65,5 & 89,4 \\
\hline 20 & 38 & 350 & 7,0 & 24,2 & 101,1 \\
\hline 28 & 38 & 122 & 3,2 & 8,6 & 86,8 \\
\hline 24 & 38 & 221 & 10,0 & 11,0 & 87,0 \\
\hline médias & 30,6 & 301,5 & 5,6 & 17,5 & 92,3 \\
\hline $\mathrm{dp}$ & $\pm 5,5$ & $\pm 109,1$ & $\pm 2,0$ & $\pm 15,4$ & $\pm 5,6$ \\
\hline
\end{tabular}

Na Tabela 4 são apresentadas as proporções de gestantes com valores deficientes, duvidosos e adequados dos três nutrientes estudados. 
Tabela 4 - Freqüência de gestantes deficientes, com deficiência duvidosa e com níveis séricos adequados para vitamina B12, folato e ferritina.

\begin{tabular}{llrc}
\hline Interpretação & B12 & Folato & Ferritina \\
\hline Deficientes & $11,8 \%$ & $0 \%$ & $47,1 \%$ \\
Duvidosos & $11,8 \%$ & $64,7 \%$ & $23,5 \%$ \\
Adequados & $76,4 \%$ & $35,3 \%$ & $29,4 \%$ \\
\hline
\end{tabular}

\section{Discussão}

Dentre as anemias carenciais que acometem as gestantes, a mais freqüente é a deficiência de ferro, seguida pelas deficiências de folato e vitamina B $12^{3,14,18}$. Neste trabalho, verificamos maior freqüência de deficientes nos estoques de ferro, seguida pela deficiência de vitamina B12 e não encontramos nenhuma gestante apresentando deficiência de folato mesmo sendo portadora de feto com DTN, adotando-se os valores de normalidade referidos na metodologia deste estudo.

Alguns autores defendem a fortificação dos alimentos com folato, apesar do risco de mascaramento dos niveis baixos de vitamina B 12 preexistentes, escondendo assim a anemia macrocítica ${ }^{4}$.

Embora Bock \& $\mathrm{Marsh}^{4}$, tenham relatado que os benefícios da suplementação sobrepujam os seus inconvenientes, Brantigam ${ }^{5}$, observa que a deficiência de B12 é um problema comum no idoso, e ainda que esta deficiência é uma condição não benigna podendo acarretar problemas neurológicos graves em razão da ausência de sintomas alertando sobre a anemia.

Beresford $^{2}$ apoia a fortificação com ácido fólico em cereais matinais, mas questiona o seu nivel, pois pode-se mascarar a anemia perniciosa (por deficiência de vitamina B12) que pode ser seguida de uma futura deterioração do sistema nervoso.

Quando ocorre somente deficiência de vitamina $\mathrm{B} 12$ e/ou deficiência de ácido fólico, o tamanho dos eritrócitos tende a ser maior que o normal, com isso o volume corpuscular médio (VCM) é geralmente maior que 100 fentolitros. Podemos verificar que este índice parece não ser um bom indicador para diagnóstico de deficiências de vitamina B12 em gestantes pois quando ocorre deficiência de ferro concomitante à deficiência de B12 e/ou deficiência de ácido fólico, este índice tende a valores médios dentro do intervalo de normalidade ${ }^{3}$. Em nosso estudo pode-se observar que os valores do VCM nos 17 casos, estão dentro do intervalo de normalidade (valor de referência para mulheres é de $92 \pm 9$ fentolitros), independente de haver deficiência de vitamina B12. Das quatro gestantes que apresentaram deficiência de vitamina B12, três apresentavam concomitante deficiência de ferro.

A porcentagem de gestantes deficientes em vitamina B12 sérica encontrada neste estudo foi de $11,8 \%$, menor que a encontrada por Black et al. ${ }^{3}$ (30\%) em grupo de gestantes na zona rural do México. Nestes dois estudos, a mesma taxa de deficientes em ácido fólico foi verificada, ou seja, não houve nenhum caso de deficiência de folato plasmático.

Bailey em 1995 realizando um estudo com relação a recomendações de ingestão de folato na dieta e observou que esta é semelhante em todo o mundo. O enfoque geral para minimizar a freqüência dos DTN é centrado no aumento do consumo de alimentos com folato que incluem legumes verdes e frutas cítricas ${ }^{1}$.

Em função destes achados, acreditamos ser importante o aumento da quantidade de folato para as gestantes por meio do consumo alimentar, visto que a demanda nesta fase é maior. A suplementação vitamínica deve ser realizada com cautela e monitorizada por exames laboratoriais.

Mansouri e Lipschitz ${ }^{13}$ relataram que antes de se iniciar uma terapia com folato em pacientes idosos, é importante se excluir a deficiência de vitamina $\mathrm{B} 12$, já que o tratamento com folato pode agravar as anormalidades neurológicas nesta última condição. É relevante citar também que a carência grave de vitamina B12 pode originar infertilidade e esterilidade completa conforme estudo de Jackson et al. ${ }^{11}$.

É pertinente citar as dificuldades para se estabelecer valores de referência dos nutrientes estudados pois estes podem sofrer variações de acordo com a idade do paciente, grupo étnico, estado de saúde, se a gestação, idade gestacional, e ainda, é dependente da metodologia laboratorial utilizada. O ideal seria que cada região geográfica tivesse a sua curva de referência, da qual hoje não dispomos.

Sabendo-se que a suplementação com ácido fólico pode mascarar a anemia por deficiência de B12 e com os resultados encontrados neste estudo (freqüência de 11,8\% de deficientes em vitamina B12 e nenhuma deficiência de folato em gestantes portadoras de fetos com DTN), é de se questionar a validade da determinação da vitamina B12 e de folato séricos antes que se institua algum plano de suplementação.

\section{SUMMARY}

Purpose: to determine folate, vitamin $B 12$ and ferritin levels in patients whose fetuses presented neural-tube defects (NTD). 
Blood folate and vitamin B12 act as cofactors of enzymes involved in DNA biosynthesis. Interruption of this process may block neural-tube closing. Vitamin supplementation with folate may reduce occurrence rates and recurrence of NTD, although there is concern about the fact that this prevention may mask vitamin B12 deficiency.

Methods: vitamin $B 12$ and ferritin determinations by enzyme immunoassay with microparticles and folic acid determination using the ion capture method (IMx ABBOTT).

Results: the percentage of pregnant women with vitamin $B 12$ deficirncy (serum levels $<150 \mathrm{pg} / \mathrm{ml}$ ) was $11.8 \%$. There was no case of folate deficiency (serum levels $<3.0 \mathrm{ng} / \mathrm{ml}$ ) and prevalence of pregnant women with iron store deficiency was $47.1 \%$ (serum levels $<\mathrm{ng} / \mathrm{mg}$ ).

Conclusions: occording to the results obtained in this study (prevalence of $11.8 \%$ of vitamin 112 and $0 \%$ offolate deficient pregnant women) we suggest that supplementation should be administered after serum vitamin B12 determination.

KEY WORDS: Prenatal care. Folic acid. Vitamin supplementation. Fetal malformations. Neural-tube defects.

\section{Agradecimentos}

Aos médicos, enfermeiras e psicólogas das equipes do pré-natal e da ultra-sonografia do Setor de Medicina Fetal da Disciplina de Obstetrícia da UNIFESP - Escola Paulista de Medicina.

\section{Referências}

1.Bailey LB. Folate in health and disease: Folate requirementes and dietary recommendations. New York: Marcel Dekker; 1995. p. 113-51.

2.Beresford SA. How do we get enough folic acid to prevent some neural tube defects? Am J Public Health 1994; 84: 348-50.

3.Black AK, Allen LH, Pelto GH, de Mata MP, Chávez A. Iron, vitamin B12 and folate status in Mexico: associated factors in men and women and during pregnancy and lactation. J Nutr 1994; 124: 1179-88.

4.Bock G, Marsh J. eds. Neural tube defects. West Sussex, England. John Wiley; 1994.

5.Brantigam CO. Folate supplementation and the risk of masking vitamin B12 deficiency. JAMA 1997; 277: 884-5.

6.Brunoni D. Alto risco genético: aspectos neonatais. Pediatr Mod 1986; 21: 415-6, 20, 22.
7.Centers for disease control and prevention (CDC). Recommendations for use of folic acid to reduce number of spina bifida cases and other neural tube defects. JAMA 1993; 269: 1233, 1236-8.

8.Cha SC. Prevenção dos defeitos do tubo neural. In: Moron AF, Cha SC, Isfer EV. Abordagem multiprofissional em Medicina Fetal. São Paulo: Escritório Editorial; 1996. p. 99-106.

9.Chanarin I. Megaloblastic anaemia, cobalamin, and folate. J Clin Pathol 1987; 40: 978-84.

10.International Nutritional Anemia Consultative Group (INACG). Measurements of iron status. Kansas City, USA: INACG; 1985. p.75.

11.Jackson IMD, Doig WB, McDonald G. Pernicious anaemia as a cause of infertility. Lancet, 1967; 2: 1159-60.

12.Luke B. Nutrição proteica materna e crescimento fetal. In: Luke B. Nutrição materna. São Paulo: Roca; 1981. p. 37-57.

13.Mansouri A, Lipschitz DA. Anemia em pacientes idosos. Anemia. Clín Méd Am Norte, 1992; 3: 635-6.

14.Martins IS, Alvarenga AT, Siqueira AAF, Szarfarc SC, Lima FD. As determinações biológicas e social da doença: um estudo de anemia ferropriva. Rev Saúde Pública 1987; 21: 73-89.

15. O' Rahilly R, Muller R. Neurulation in the normal human embryo. In: Bock, G; Marsh, J. editors. Neural tube defects. West Sussex, England: John Wiley; 1994.

16. Organizacion Mundial de La Salud. Necessidades de ácido ascórbico, vitamina $\mathrm{D}$, vitamina $\mathrm{B} 12$, folato y hierro. Ginebra; 1970. Série de Informes Técnicos, 452:38.

17.Page RL $2^{\text {nd }}$, Jones KW, Jebaily GC. Can women live on bread alone? Folic acid supplementation revisited. J S C Med Ass 1997; 93: 57-62.

18.Rapaport SL. Anemias megaloblásticas. In: Rapoport SL. Hematologia: introdução. 2 ed. São Paulo: Rocca; 1990. p. 42-60.

19.Rose NC, Mennuti MT. Periconceptional folate supplementation and neural tube defects. Clin Obstet Gynecol 1994; 37:605-20.

20.Smithells RW, Sheppard S, Schorah CJ, Seller MJ, Nevin NC, Harris R, et al. Possible prevention of neural-tube defects by periconceptional vitamin supplementation. Lancet 1980;1: 339-40.

21.Tedesco JJA, Silva EP, Piato S, Wajntraub I, Assad W Jr, Crozera YR, et al. Niveis plasmáticos de ferritina durante a gravidez. J Bras Ginecol 1988; 98: 277-80.

22.World Health Organization. Nutritional anaemias. Geneva; 1968. Technical Report Series, 405:23. 